\title{
Osteopoikilosis in the knee
}

\section{Emilio Manuel Padín-Paz MD, José Antonio Díaz-Peromingo MD}

See related practice articles by Di Primio, page 456 and by Hii and Tan, page 460
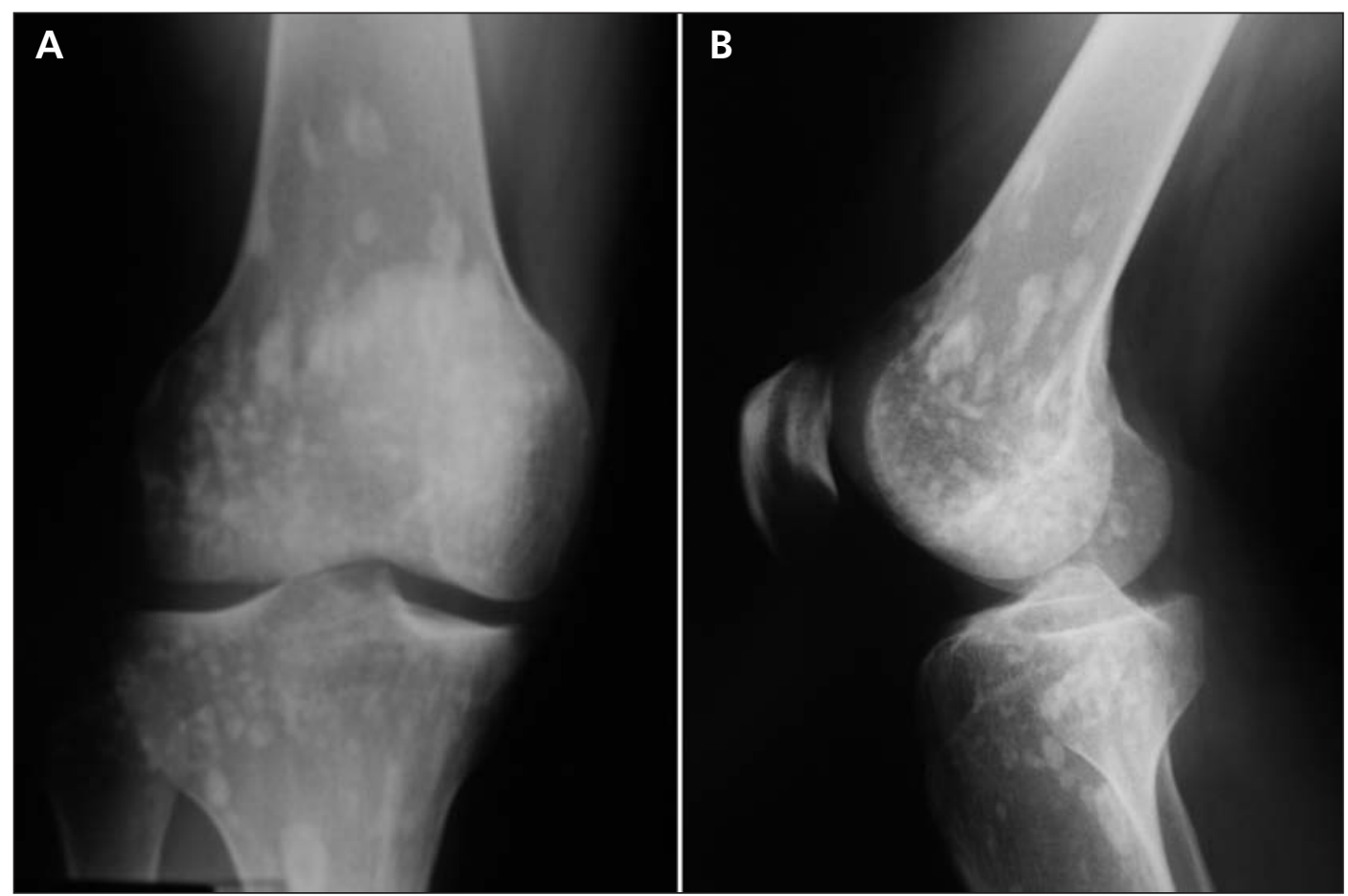

Competing interests: None declared.

This article has been peer reviewed.

Correspondence to: Dr. José Antonio DíazPeromingo, jose.antonio.diaz.peromingo @ sergas.es

Affiliation: From the Department of Internal Medicine, Hospital da Barbanza, Riveira, Spain

CMAJ 2011. DOI:10.1503 /cmaj.081519

Figure 1: Frontal (A) and lateral (B) views of the knee of a 31-year-old man. Circumscribed, periarticular scleroses can be seen, which are consistent with a diagnosis of osteopoikilosis.

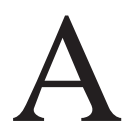
31-year-old man presented to the emergency department with bilateral knee pain after having had a minor fall in the street. On examination, he was in no distress, and he had scratching and bruising over the anterior aspects of both knees. There was some pain to palpation over the right knee, accompanied by mild suprapatellar swelling. Both knees had a full passive range of motion. No other joints were affected, and his physical examination was otherwise unremarkable. $\mathrm{He}$ was in good health and had no history of serious illness. A radiographic study of the knees showed circumscribed sclerotic areas near the ends of the tibia and femur (Figure 1). These are consistent with a diagnosis of osteopoikilosis. ${ }^{1}$ A computed tomography scan of both knees to rule out bone metastases was normal. A radionuclide scan with technetium $99 \mathrm{~m}$ was not available.

Our patient's pain from contusions improved quickly after he started taking ibuprofen (400 mg twice daily), with full resolution of his symptoms after two days.

\section{Reference}

1. Di Primio G. Benign spotted bones: a diagnostic dilemma. CMAJ 2011;183:456-9. 